\title{
Promoting Critical and Design Thinking Activities to Tackle Sustainable Development Goals in Higher Education
}

\author{
Denis Gillet \\ School of Engineering \\ École Polytechnique fédérale de Lausanne (EPFL) \\ Lausanne, Switzerland \\ denis.gillet@epfl.ch
}

\author{
Isabelle Vonèche-Cardia \\ School of Engineering \\ École Polytechnique fédérale de Lausanne (EPFL) \\ Lausanne, Switzerland \\ isabelle.voneche-cardia@epfl.ch
}

\begin{abstract}
Since 2016, the 17 Sustainable Development Goals (SDGs) came into force, and for the first time they include higher education. Therefore, higher institutions are finding ways to incorporate them into their teachings and research activities. This paper contributes to the literature on engineering education by providing new insights on how to implement the SDGs at the course level. It argues that combining core and transversal skills, along with case studies targeting the SDGs, is an efficient way to prepare the next generation of engineers to tackle the challenges of our society. Moreover, promoting critical and design thinking activities increases the desire of university students to put their technical knowledge and skills at the service of mankind and the planet. Finally, this paper reflects on the pedagogical changes induced by COVID-19.
\end{abstract}

Keywords-Higher Education, Global Issues, Social Media, Blended Learning, Collaborative Learning, Critical Thinking, Design Thinking, SDGs

\section{INTRODUCTION}

On January $1^{\text {st }}, 2016$, the 17 Sustainable Development Goals (SDGs), adopted by world leaders in September 2015 at a United Nations Summit, came into force. SDGs aim to combat all forms of poverty, inequality and address climate change, making sure that no one is left behind. They also include tertiary education, which is new, compared to the previous sets of development goals - the Millennium Development Goals - that focused only on primary education.

In order to integrate the SDGs in higher education, learning institutions have been invited to incorporate them into their curricula and research projects. Furthermore, the SDG Accord platform ${ }^{1}$ has been created to advance the critical role that education has in delivering the SDGs. The platform aims at encouraging learning institutions to do more to deliver the goals by reporting on their progress and by sharing their learning with each other, both at the national and international levels.

Despite these big commitments, educating students to become global citizens and increasing their perspectives on SDGs remains a challenging task. This paper contributes to the literature on engineering education by providing new insights on how to implement the SDGs at the course level.
We argue that a holistic approach, combining core and transversal skills, along with case studies targeting the SDGs is an efficient way to prepare the next generation of engineers to tackle the challenges of our society. Moreover, promoting critical and design thinking activities increases the desire of university students to put their technical knowledge and skills at the service of mankind and the planet.

To begin, this paper presents (Section II) the objectives and structure of two courses, namely the Communication and the Social Media courses taught at the Swiss Federal Institute of Technology in Lausanne (EPFL). It then shows how specific transversal skills and SDGs bring a unique value to these courses (Section III). This is clearly demonstrated by the analysis of data collected during several iterations of both courses (Section IV). Finally, the paper reflects on the pedagogical changes induced by COVID-19 (Section V) and it concludes with a perspective for the future.

\section{COURSE OBJECTIVES AND STRUCTURE}

Each academic year, the general structure of the Communication and the Social Media courses - focusing on lectures, projects, and homework-remains stable, but the focus of the projects and the topics are dynamic. In that way, the course is renewed and adapted to students' technical and societal concerns every year.

The two courses integrate the acquisition of specific core and transversal skills, which are instrumental in tackling the 21 st century challenges and the SDGs. The Organisation for Economic Co-operation and Development (OECD) annual report on education states that "proficiency in critical thinking and problem solving, and in social and emotional skills, such as teamwork, communication and cultural awareness, are all essential to ensure an individual's inclusion and constructive engagement in society" [1].

Furthermore, the importance of the skills associated to teamwork as a learning outcome for students in engineering is widely recognized by scholars [2], as well as accreditation agencies, such as the Accreditation Board for Engineering and Technology (ABET) [3].

It is also a core element of SDG 17 (partnerships for the goals). Defining shared objectives and common vocabulary among students with different backgrounds, managing tasks,

\footnotetext{
${ }^{1}$ The SDG Accord platform.
} 
or handling potential conflict that might arise in such a collaborative context, are essential for students not only to succeed in their studies and projects, but in their future career as well. SDGs are also introduced as core knowledge and as motivational anchors between the subjects taught and the societal issues.

\section{A. Communication Course}

The Communication course, is part of the global issues program offered at EPFL. The objective of this program is to sensitize all first-year students to the challenges of our society in connection with their science and engineering studies. On a first-come first-served basis, students choose one course from the following six global issues: Food, Communication, Climate, Energy, Mobility and Health. The courses are doubled in order to accommodate all first-year students which represents about 1,500 people [4]. In this paper, we focus on the Communication course, which is taught to about 150 students by the first author of this paper together with a colleague from the Faculty of Business and Economics (HEC) of University of Lausanne (UNIL).

The course runs for a total of 14 weeks (one semester) and counts for two European Credit Transfer and Accumulation System (ECTS), which means a total of 56 hours. It is divided in two parts: the first one is a series of lectures, and the second one is dedicated to teamwork (Table I). One of the lectures is common to all twelve courses on global issues and features a high-profile guest speaker. In the second part of the course, the group activities are aimed at actively putting in practice the knowledge acquired in the first part and to develop transversal skills. Students, each coming from one of the 13 EPFL Bachelor programs, form a group of five teammates and choose a topic related to communication. They prepare a poster that is submitted and presented at the end of the semester (see Table I).

The core skills tackled from a technical and societal perspective in the lectures include:

- General context and impact of past, present and future information and communication technologies;

- Social media content and the associated privacy and veracity challenges;

- Online behaviors, including creation, sharing, personalization, and inclusion, as well as influencing and decision making;

- Digital competencies, including data literacy, ethics, and skills for participating, working and learning online.

These skills are introduced in a Massive Open Online Course (MOOC) in French (the language of the course) and are debated in the classroom face-to-face or online depending on the sanitary constraints (see Section V).

The poster delivered at the end of the teamwork has to tackle a global issue related to communication. Our definition of a global issue is a problem which affects a large amount of people internationally; requires a coordinated action from several stakeholders, and include a technological and a societal dimension. The poster has to include the definition of the selected communication issue, its technical and societal dimensions, as well as its current and potential future solutions, all documented with relevant scientific references.

\section{B. Social Media Course}

The second course considered in this paper is a course on Social Media taught at the EPFL. Its objective is to enable students to critically apprehend the Human Computer Interaction (HCI) challenges associated with the design and the exploitation of social media platforms or mobile apps. This 56-hour course (2 ECTS) breaks down into four hours a week for one semester. The four hours are divided as follows: onehour lecture, one-hour project and two-hour homework.

This course is also divided in two parts: the first one is a series of lectures with an individual project as homework, and the second one is dedicated to teamwork (Table I). In the latter, four to five students work on a collaborative project related to social entrepreneurship, deliver a 10-page report, and pitch the proposed innovative social media solution in a final presentation.

The core skills tackled in the lectures of the Social Media course include:

- A general introduction to social media and the social features of cloud platforms and mobile apps;

- Usability and accessibility;

- Trust and privacy;

- Adoption and evaluation;

- Business and marketing dimensions, including value proposition canvas, pricing, and pitching;

- Introduction to the SDGs, social good and entrepreneurship.

The book by Joshua Porter on Designing for the Social $W e b$ is used to introduce some of these topics. The Design Thinking methodology is also presented, as well as Agile Development and Participatory Design approaches. These are achieved through lectures and dedicated design thinking sessions.

The typical design thinking methodology follows five successive phases that can be revisited iteratively ${ }^{2}$, namely Empathize to understanding the problem to solve, Define to formalizing the problem to be tackled, Ideate to eliciting preliminary solutions, Prototype to identifying and refining the best and feasible alternatives, and Test to validating the final solution.

In the course, the design thinking activity is implemented in three steps during the first teamwork session. First, each student has to select one of four recommended themes for social good, namely, knowledge sharing, eHealth or humanitarian technology, Information and Communication Technology (ICT) for development or sustainability, and educational technology.

Second, the students are grouped by interest and have to quickly propose an idea (15 minutes for the Empathize phase) for an innovative social media solution and pitch it to the others. Then, an anonymous vote is organized with a mobile

\footnotetext{
${ }^{2}$ https://www.interaction-design.org/literature/article/5stages-in-the-design-thinking-process
} 
app and the best solutions are selected. Students cluster around these best ideas ( 4 to 5 students per idea) and, most of the time, the original proposer becomes the team leader. This speeddating like activity is done in a limited time to trigger spontaneous ideas. It requires proper instructions and agile coaching by the educators and the teaching assistants to run smoothly and converge towards interesting collaborative projects. A special care is also taken to ensure that the number of students per team and the number of teams per theme for social good is well balanced.

Third, the newly created teams have to refine their common idea (15 min for the Define phase) and pitch it to the whole class in order to get feedback. Taking into account the feedback from the peers and the educators, each team submit a consolidated one-pager definition of their solution (30 min for the Ideate Phase). This crowd-sourcing elicitation of ideas and the inductive team composition prevent further potential conflicts during teamwork, because the teams are not imposed.

The Prototype and Test phases (last two phases of design thinking) are handled collaboratively in the other teamwork sessions. It is worth mentioning that no software implementation is required. The prototypes delivered are functional and graphical mockups. These mockups are also used for testing. This conceptual design is helping to accommodate the limited number of ECTS and the nonengineering students that can enroll in the course. However, teamwork is not limited to designing mockups. The full process of designing a novel social media solution is implemented and all dimensions tackled during lectures are covered. This is reflected in the content of the 10-page report that students submit at the end of their collaborative project. The recommended content should include: (1) Title and team description with assigned roles; (2) A pitch as a compact and effective introduction; (3) User scenarios; (4) Social dimensions and features, as only solutions with a strong social dimension are accepted; (5) Value proposition and pricing; (6) Mockups; (7) Evaluation carried out with friends and family using the mockups; and (8) Conclusion and self-reflection on the design process and its outcome.

TABLE I. THE SYLLABUS OF THE TWO COURSES

\begin{tabular}{|c|c|}
\hline Weeks & Part 1 - Lectures \\
\hline 1 to 6 & Course specific content \\
& including one or more guest speakers \\
\hline 7 & Part 2 - Practice \\
\hline 8 to 12 & Teamwork \\
\hline & \\
\hline 13 & Poster or report submission \\
\hline 14 & Oral presentation \\
\hline
\end{tabular}

\section{TRANSVERSAL SKILLS AND SDGS}

In this Section we describe how critical thinking, interdisciplinarity, collaboration, and SDGs are integrated and tackled in the two courses.

\section{A. Critical thinking}

Critical thinking is commonly listed as one of the "21st century skills" [5].

In the Communication course, critical thinking is developed in relation to gathering and exploiting relevant scientific literature, as well as in getting involved in debates and teamwork. For the latter, the multiple iterations of the program (almost ten years) showed that writing group reports every week (see Section III.C) is a useful self-reflection exercise, which is promoting self-assessment.

Moreover, critical thinking is implemented in the midterm assignment. Students are asked to submit a two-page self-reflection report on the relations between the communication perspectives tackled in the lectures and the topic they chose for their poster. This new mid-term assignment replaces the previous multiple-choice question (MCQ) test, transforming a summative evaluation into a formative one.

In the Social Media course, critical thinking is introduced by implementing and promoting self-reflection through assignments, teamwork, and peer evaluation.

Students are assigned with two projects: an individual and a collaborative one. In the individual project, students select an existing social media platform, assess its social features and usability, and hand over a two-page report. As such, it is a critical thinking activity, because assessing a platform requires critical analysis.

In the collaborative project (teamwork) students design a new social media platform for social impact. Critical thinking is already present in the first design thinking session described in Section II.B. Moreover, the students are required to present the status of their teamwork three weeks before completion in order to discuss progress and define priorities.

Last but not least, students are also asked to evaluate their peers on two occasions. First, they have to assess eight anonymized individual reports as a mid-term assignment (see Table I and Section IV.A). Second, they evaluate the oral presentations done by their peers at the end of the course, and vote for the best one. Bonuses are given to the best reports and presentations selected by the students.

\section{B. Interdisciplinarity}

The particularity of the Communication course is its focus on interdisciplinarity, which is tackled at various levels. First, two educators with different background teach the course together: one is from science and engineering and one from social and human sciences. Each teacher contributes according to his background, giving a technical and a societal perspective simultaneously. Two of the four teaching assistants are recruited at EPFL and the other two at UNIL.

Second, students come from different bachelor programs and are mixed for group activities. It is interesting to note that even though students have just started their specific curriculum, they are already very entrenched in their discipline. Students from the architecture study program 
think, for instance, that the rest of their peers have poor taste when it comes to designing the poster.

Finally, the content of the course is also interdisciplinary by nature, because it presents the communication issues from a technical and a societal perspective.

In the Social Media course, interdisciplinarity is also intrinsic to the subject matter, as well as embodied by the students' and educators' academic provenance. The course content deals with human computer interaction (computer science and psychology), tangible objects and internet of things (engineering), as well as marketing strategies such as value proposition and pricing (business).

Educators in this course also come from the EPFL and UNIL. The difference with the other course is that the students come from those two institutions as well. It is relatively rare in Switzerland to mix engineering students with business students, because it is quite challenging. Organizational constraints such as schedule, enrollment, number of students per institutions and number of credits given for the course represent an administrative burden that few universities are willing to bear. For instance, both universities had to accept the fact that the number of credits for students were different: the engineering students receive 2 ECTS and business students receive 3 ECTS.

Although the teams are created organically during the first teamwork session, more than half of the teams are mixing science and engineering students with business students. This shows that the students understand the benefits of bringing together complementary competences.

\section{Collaboration}

In the Communication course, the main outcome of teamwork is a poster and its presentation. According to [2], most programs do little to teach teamwork skills assuming that "experience is the best teacher". They advocate to be more proactive in the teaching of teamwork skills, which is the case here, because teamwork progresses are reviewed every week. Groups have to hand in a brief report, which not only reflects and summarizes the work done by each member independently, but it also assigns individual tasks for the upcoming week. The reports are designed to help educators assess the progress of the work, but also to identify potential conflicts, such as dealing with free riders. As mentioned before, it also became a useful self-reflection exercise.

The main outcome of teamwork in the Social Media course is a report and a presentation. Depending on the number of students following the course each year, about a dozen teams are created and divided into four themes related to social good: Knowledge sharing, eHealth or humanitarian technology, ICT for development or sustainability, and educational technology. For each theme, a teaching assistant is coaching the associated teams, from a methodological and a managerial point of view. As the students are coming from two walking-distance campuses, they tend to meet physically or virtually (see Section V) at the scheduled course hours.

\section{SDGs}

The six SDGs tackled more directly in the Communication course (Table II) are Quality Education (SDG4) potentially achieved with ubiquitous digital access, as well as open educational resources and platforms; Gender Equality (SDG5) with alternative learning modalities and micro business opportunities; Decent work and economic growth (SDG8) with new ICT-based business models; Industry, innovation and infrastructure (SDG9) with emerging technologies, novel entrepreneurships opportunities and ubiquitous networking facilities; Peace, justice and strong institutions (SDG16) with new crowd-based governance models; and Partnerships for the goals (SDG17) intrinsically related to the interdisciplinarity and collaboration dimensions of the course.

In the Social Media course, specific SDGs are tackled in the teamwork depending of the chosen themes for social good. The three main SDGs covered by these themes are listed in Table II.

TABLE II. MAIN SDGS RELATED TO THE TWO COURSES

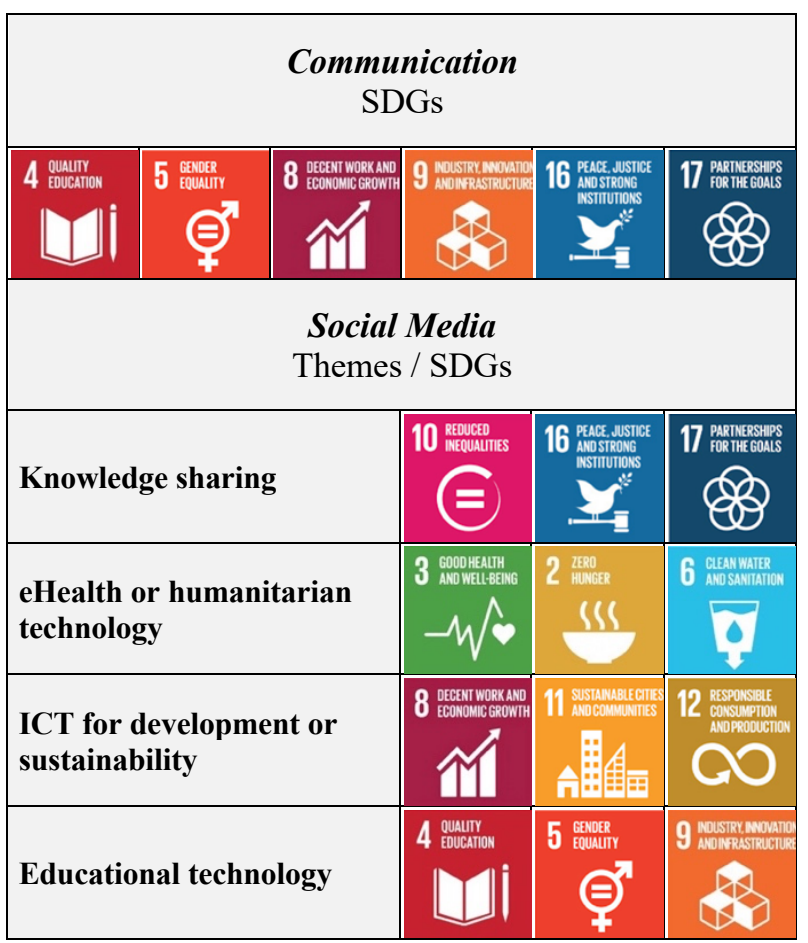

\section{PedAgOgICAL IMPLEMENTATIONS}

Quantitative outcome in terms of critical thinking, interdisciplinarity, and SDGs is presented in this Section. The analyses are based on five iterations of the Communication course and four iterations of the Social Media one. The latter had more iterations, but we took into account only the last four, because it is when business students joined the class.

The collaboration dimension is not discussed here, as we do not have yet a platform to gather analytics on the interaction between the students. Starting next year, we will implement the Graasp.eu open access digital education platform that is supporting online design thinking activities, amongst other pedagogical scenarios, and is offering build-in learning analytics features.

\section{A. Critical thinking}

As part of the critical thinking activity of the Social Media course (Section III.A), students have to complete the peer evaluation of eight individual reports submitted by their colleagues. It is important to stress that peer evaluation is working well only if the rules are clearly defined. Students are therefore informed that their evaluation will count more if it is highly correlated with the ones of the experts (educators and teaching assistants). As a good correlation is typically 
achieved (Fig. 1), the peer evaluation usually counts for two third of the grade of the individual reports. The correlation between the evaluation by peers and experts was between 0.89 and 0.72 over the last four years.

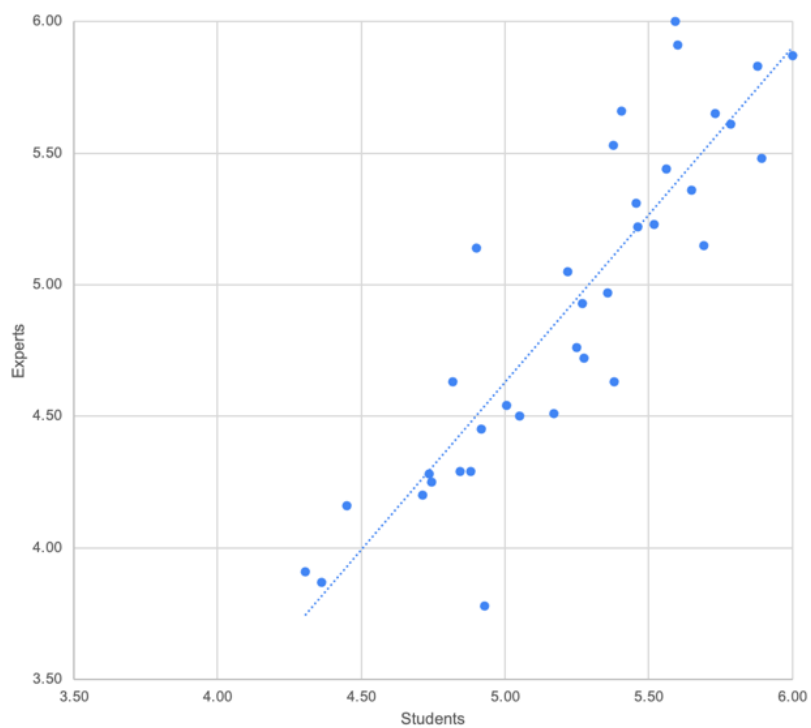

Fig. 1. Correlation between the peer and expert evaluation of the individual reports in the 2021 Social Media Course (min grade is 1 , max is 6, pass at 4).

In addition of being a critical thinking activity, this peer evaluation is also contributing to the understanding of the core concepts of value proposition and usability through examples, i.e., the platforms selected and analyzed by the peers.

\section{B. Interdisciplinarity}

The Communication course can be selected by students from 13 bachelor programs. Over the years, the balance between the programs has been quite stable (see Fig. 2) and somehow reflects their respective size. It is interesting to note that students from computer science and communication systems represent only one-third of the students, although the communication topic is closer to their discipline. This also shows that students from other programs understand the importance of communication issues in our society.

The Social Media course is elective for students from EPFL and UNIL. However, there is a size limit for the course of 45 students from EPFL and 15 from UNIL to strengthen interdisciplinarity. Fig 3 shows the proportion of students from the electrical and mechanical engineering master programs offered by the school of Engineering (ENG) at EPFL, from the computer science (INF) and communication systems (COM) master programs offered by the School of Computer and Communication Sciences at EPFL, as well as from the marketing and management of technology master programs offered by the Faculty of Business and Economics (HEC) at UNIL.

The fact that the majority of students are from computer science reflects the anchor of software engineering and human computer interaction disciplines in their program, while the significant proportion of students from communication systems reflects the increasing importance of trust and privacy in social media platforms and apps. The proportion of $26 \%$ of students from HEC corresponds to the enrolment limit, showing their interest for this interdisciplinary course. The recent development of social media solutions integrating
Internet of Things (IoT) is explaining the increasing number of engineering students enrolled in the course.

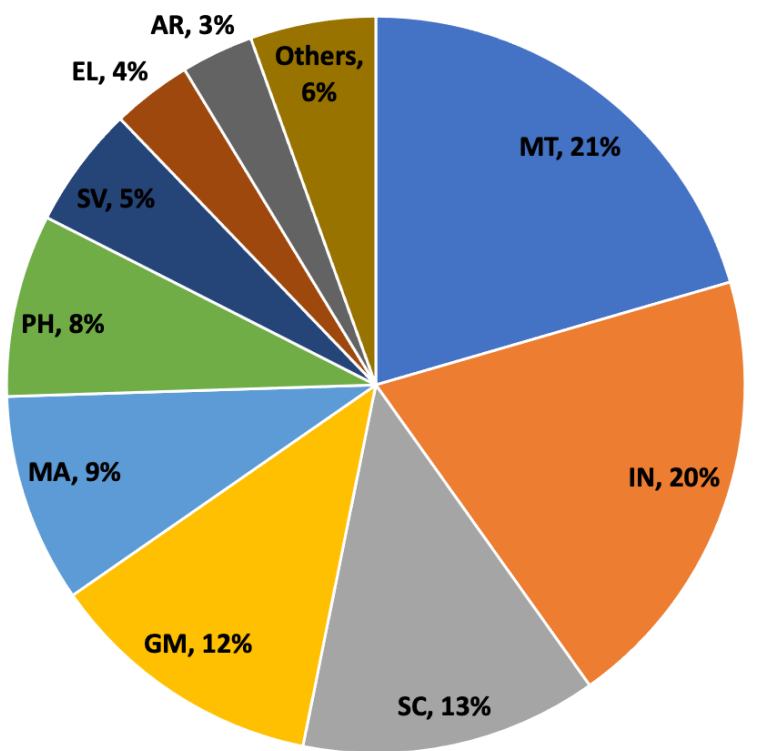

Fig. 2. Average percentage of students from the various study programs enrolled in the Communication course over the last five years (MT: microengineering, IN: Computer science, $\mathrm{SC}$ : Communication systems, GM: Mechanical engineering, MA: Mathematics, PH: Physics, SV: Life science, EL: Electrical engineering, and AR: Architecture).

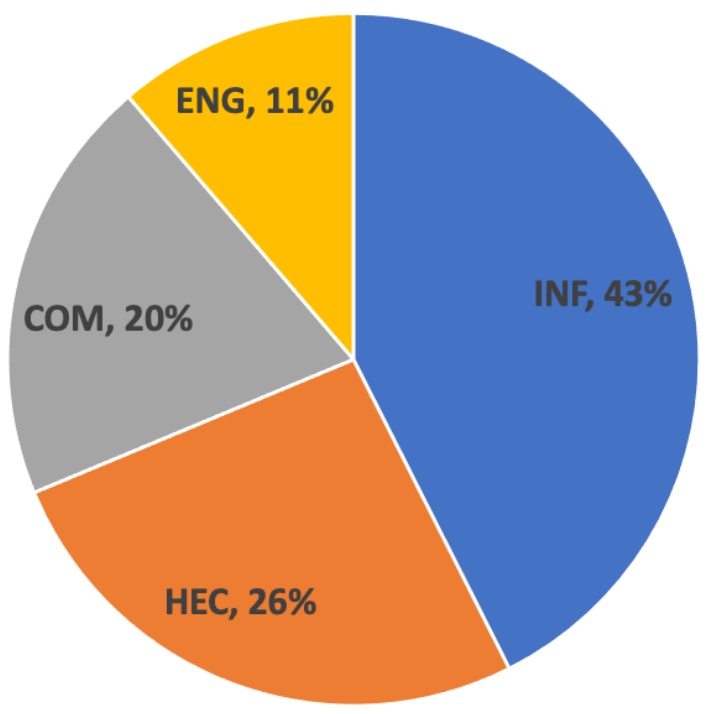

Fig. 3. Average percentage of students from the various study programs enrolled in the Social Media course over the last 4 years (ENG: Electrical and mechanical engineering, INF: computer science; COM: Communication systems, HEC: Marketing and management of technology).

\section{C. $S D G S$}

In the Communication course, students are required to prepare a poster related to issues in this domain (Section II.A). Table III lists the key topics and occurrences that were extracted, coded, and translated (French to English) from the 113 titles of the posters collected over the last five years. These occurrences show the importance of the topics for the students.

The temporal evolution of the topics is not illustrated. However, we have noted that fake news became an issue while 
Donald Trump was the President of the USA and digital education became more prominent at the beginning of the COVID-19 pandemics.

TABLE III. KEY TOPICS EXTRACTED FROM THE TITLES OF THE POSTERS IN THE COMMUNICATION COURSE

\begin{tabular}{|l|c|}
\hline Topics & Occurence \\
\hline Influence and manipulation & $12 \%$ \\
\hline Privacy & $12 \%$ \\
\hline Democracy & $11 \%$ \\
\hline Artificial intelligence & $8.0 \%$ \\
\hline Access to information and education & $8.0 \%$ \\
\hline Fake news & $6.2 \%$ \\
\hline Diversity & $4.4 \%$ \\
\hline
\end{tabular}

In the Social Media Course (Table IV), the pandemics has triggered more interest in eHealth in 2021 and in Educational Technology in 2020, including apps to manage vaccines and solutions for tele-diagnosis, as well as add-ons for online education. In 2019 there was a strong focus on sharing tips, experience, goods, food, and facts. In 2018, there was a raising interest for social media solutions relying on augmented reality with applications to knowledge sharing and educational technology.

TABLE IV

NUMBER OF PROJECTS PER THEME IN THE SOCIAL MEDIA COURSE

\begin{tabular}{|l|c|c|c|c|}
\hline \multicolumn{1}{|c|}{$\begin{array}{c}\text { Number of teams } \\
\text { per theme }\end{array}$} & $\mathbf{2 0 2 1}$ & $\mathbf{2 0 2 0}$ & $\mathbf{2 0 1 9}$ & $\mathbf{2 0 1 8}$ \\
\hline Knowledge sharing & 3 & 3 & 7 & 7 \\
\hline $\begin{array}{l}\text { eHealth or humanitarian } \\
\text { technology }\end{array}$ & 4 & 2 & 1 & 1 \\
\hline $\begin{array}{l}\text { ICT for development or } \\
\text { sustainability }\end{array}$ & - & 3 & 2 & 1 \\
\hline Educational technology & 3 & 3 & - & 4 \\
\hline
\end{tabular}

\section{From BlENDEd LEARNING TO FULLy ONLINE}

Blended learning has multiple definitions [6]. We rely on the definition of [7] who sees it as a combination of different delivery media to promote meaningful and motivating learning through different synchronous and asynchronous strategies.

In this Section, we highlight how the blended learning modality existing before the COVID-19 pandemics, helped in implementing a fully online education scheme during the full confinement (Spring semester 2020) and the following academic year (Fall and Spring semesters 2021) where students could only be on campus for hands-on sessions every three weeks.

\section{A. Before COVID-19}

In the Communication course, lectures and part of the questions were already handled asynchronously. Students were watching the course in a MOOC with a related chatroom, where they could ask questions. Physical face-to-face classrooms still existed, but they started with a brief recap of the course and were followed by a debate highlighting some specific issues. The impulse for the topic of the debate could either come from the educators or from asynchronous questions raised by students in the chatrooms. In short, we used the flipped classroom pedagogical method "which employs asynchronous video lectures and practice problems as homework, and active, group-based problem solving activities in the classroom" [8].

In the Social Media course, the lectures were done face-toface every Friday.

In both courses the teamwork part (see Table I) was also done in a classroom, but it was not mandatory for students to be there. Some students chose to work together elsewhere, hence renouncing to getting direct support by teaching assistants.

\section{B. During COVID-19}

"Traditionally, societies and individuals have adopted a pattern of continuous maintenance learning interrupted by short periods of innovation stimulated largely by the shock of external events" [9]. We were subjected to this shock-based treatment during the COVID-19 pandemics.

In the Communication course, the only change was that debates were held via Zoom rather than in the classroom. It ended up working well thanks to the organization of small breakout rooms of approximately ten students for discussion, instead of a full class (about 150 students). Smaller groups enabled lively debates and the online format ended up to be much more participative than the physical one. Furthermore, students were more inclined to switch on their cameras within small groups and they kept this habit for online classrooms.

In the Social Media course, lectures were either prerecorded or given live online via Zoom. The design thinking activities of the first teamwork session were much more challenging. They were held online, but a lot of the interactions that make these activities so compelling for students were lost. Online coaching for groups was also a mixed experience. Some groups were highly involved and participated in all pre-scheduled coaching meetings. Interestingly and not surprisingly, they also performed significantly better than other groups who hardly used online coaching.

In both courses, the teamwork part was held remotely but with no control of the modality. Students mostly reported their progresses to teaching assistants during pre-scheduled meetings using Zoom and some other social media chat apps, such as WhatsApp or Discord.

Based on these experiences, we learned the following lessons. First, it is crucial to hold debates in small groups and the online format has no negative impact, it even helps logistically. Second, there is a clear need for a dedicated online platform for collaboration in general and design thinking in particular. This is one of the aspects we are currently working on for the course next year. Third, online coaching works, but there has to be either incentive or strong rules otherwise students will scarcely use this resource. 


\section{CONCLUSIONS}

This paper shows that societally-relevant courses provide a solid platform for the development of core and transversal skills. Furthermore, it proposes original methodologies, which can be implemented at scale in higher education institutions. In this regard, it answers one of the most important question raised in The global state of the art in engineering education [10], which is to figure out how to offer a quality of education at scale.

Two examples of engineering courses are considered as use cases. They show how effectively interdisciplinarity, collaboration, and the SDGs can be integrated to fulfil the expectations of the students to contribute to social good, while becoming skillful and responsible engineers and scientists.

The crowd-sourcing approach implemented to define the topics for teamwork is a strong motivational incentive for learning. It also provides a snapshot of the actual concerns of the students and make them think about the solutions their generation can invent for the sustainability of mankind and the planet.

Finally, the blended learning modality progressively developed in higher education during the last decade has proven to be effective to move to fully online learning during COVID-19. It is paving the way for more agile teaching and learning schemes for the upcoming years, based on the lessons learned. Last but not least, it is aligned with modalities and practices the students will experience in their future workplace.

\section{REFERENCES}

[1] OECD, Education at a Glance 2017: OECD Indicators. OECD, 2017. doi: 10.1787/eag-2017-en.

[2] R. Lingard and S. Barkataki, "Teaching teamwork in engineering and computer science," in 2011 Frontiers in Education Conference (FIE), Rapid City, SD, USA, Oct. 2011, pp. F1C-1-F1C-5. doi: 10.1109/FIE.2011.6143000.

[3] "2020-21-ETAC-Criteria.pdf." Accessed: Sep. 15, 2021. [Online]. Available: https://www.abet.org/wp-content/uploads/2020/02/202021-ETAC-Criteria.pdf

[4] A. Holzer, S. Bendahan, I. Vonèche-Cardia, and D. Gillet, "Early Awareness of Global Issues and Development of Soft Skills in Engineering Education: An Interdisciplinary Approach to Communication," p. 6.

[5] Q. Wang, Y. Cheng, and N. C. Liu, Building world-class universities different approaches to a shared goal. Rotterdam: Sense Publishers, 2013. Accessed: Jun. 02, 2021. [Online]. Available: https://ebookcentral.proquest.com/lib/uvic/detail.action?docID=3034 830

[6] N.-S. Chen, C.-W. Wei, Kinshuk, Y.-R. Chen, and Y.-C. Wang, "Bridging the Gap Between Face-to-Face and Cyber Interaction in Holistic Blended Learning Environments," in Handbook on Information Technologies for Education and Training, $\mathrm{H} . \mathrm{H}$. Adelsberger, Kinshuk, J. M. Pawlowski, and D. G. Sampson, Eds. Berlin, Heidelberg: Springer Berlin Heidelberg, 2008, pp. 239-259. doi: 10.1007/978-3-540-74155-8_13.

[7] S. Dakduk, Z. Santalla-Banderali, and D. van der Woude, "Acceptance of Blended Learning in Executive Education," SAGE Open, vol. 8, no. 3, p. 215824401880064, Apr. 2018, doi: 10.1177/2158244018800647.

[8] J. Bishop and M. Verleger, "The Flipped Classroom: A Survey of the Research," in 2013 ASEE Annual Conference \& Exposition Proceedings, Atlanta, Georgia, Jun. 2013, p. 23.1200.1-23.1200.18. doi: 10.18260/1-2--22585.

[9] J. W. Botkin, M. Elmandjra, and M. Malitza, "BRIDGING THE HUMAN GAP,”p. 180, 1998.

[10] R. Graham, "Global state of the art in engineering education - March 2018," p. 170. 